\title{
Advanced Breast Angiosarcoma Completely Responding to Gemcitabine-Containing Chemotherapy
}

\author{
Zhi-Guo Luo ${ }^{a, b *}$ Qian Wang ${ }^{a, b *}$ Wei Peng ${ }^{a, b}$ Xi-Chun Hu Xiao-Nan Hong $^{a, b}$ \\ ${ }^{a}$ Department of Medical Oncology, Fudan University Shanghai Cancer Center, \\ ${ }^{b}$ Department of Oncology, Shanghai Medical College, Fudan University, Shanghai, China
}

\section{Keywords}

Breast neoplasm · Angiosarcoma · Lung metastases · Gemcitabine · Vincristine · Cisplatin · Chemotherapy

\section{Summary}

Background: For patients with anthracycline-resistant metastatic angiosarcoma, there is currently no available standard for second-line therapy, and a need exists for novel effective regimens to improve response rates. Case Report: We report here on a case of a primary angiosarcoma of both breasts in a 34-year-old woman presenting with lung metastases. Upon completion of 3 cycles of the MAID regimen (mesna, adriamycin, ifosfamide, dacarbazine), computed tomography showed disease progression. Subsequently, a secondline chemotherapy was started using the GVP regimen (gemcitabine, vincristine, cisplatin). Complete response of the lung metastases was achieved after 6 cycles of treatment. Conclusion: In the absence of an effective therapy among patients with anthracycline-resistant metastatic breast angiosarcoma, a GVP chemotherapy regimen can be performed as a selective option.

\section{Introduction}

Primary angiosarcoma of the breast is a rare and highly aggressive malignancy which accounts for about $0.05 \%$ of malignant breast neoplasms [1,2]. The 3-year disease-free survival and overall survival are 14 and $38 \%$, respectively [3]. Bilateral primary breast angiosarcoma is even more infrequent. Only 1 case of metachronous bilateral angiosarcoma of

*These authors contributed equally to this study.

\section{KARGER}

Fax +497614520714

Information@Karger.de

www.karger.com

\section{(c) 2012 S. Karger GmbH, Freiburg}

$1661-3791 / 12 / 0075-0414 \$ 38.00 / 0$

Accessible online at:

www.karger.com/brc

\section{Schlüsselwörter}

Mammatumor · Angiosarkom - Lungenmetastasen . Gemcitabin · Vincristin · Cisplatin · Chemotherapie

\section{Zusammenfassung}

Hintergrund: Für Patienten mit anthrazyklinresistentem metastasierten Angiosarkom existiert momentan keine Standard-Zweitlinientherapie, und es besteht Bedarf an neuen effektiven Regimen zur Verbesserung der Ansprechraten. Fallbericht: Wir berichten von einem Fall von primärem, bilateralen Angiosarkom der Brust bei einer 34-jährigen Patientin mit Lungenmetastasen. Nach 3 Zyklen des MAID-Regimes (Mesna, Adriamycin, Ifosfamid, Dacarbazin) zeigte die computertomographische Untersuchung ein Fortschreiten der Erkrankung. Daraufhin wurde eine Zweitlinienchemotherapie mit dem GVPRegime (Gemcitabin, Vincristin, Cisplatin) begonnen. Nach 6 Behandlungszyklen konnte ein komplettes Ansprechen der Lungenmetastasen verzeichnet werden. Schlussfolgerung: In Abwesenheit einer effektiven Therapie für Patienten mit anthrazyklinresistentem metastasierten Angiosarkom der Brust stellt das GVP-Chemotherapieregime eine Behandlungsmöglichkeit dar.

the breast has been reported thus far [4]. We herein report a case of complete remission of anthracycline-resistant lung metastases of a bilateral primary angiosarcoma of the breast after treatment with the GVP chemoregimen.

\section{Case Report}

A 34-year-old female patient had noticed diffuse enlargement of both breasts by more than one-third over a 1-year period, accompanied by nipple retraction, occasional galactorrhea, local skin thickening, and 


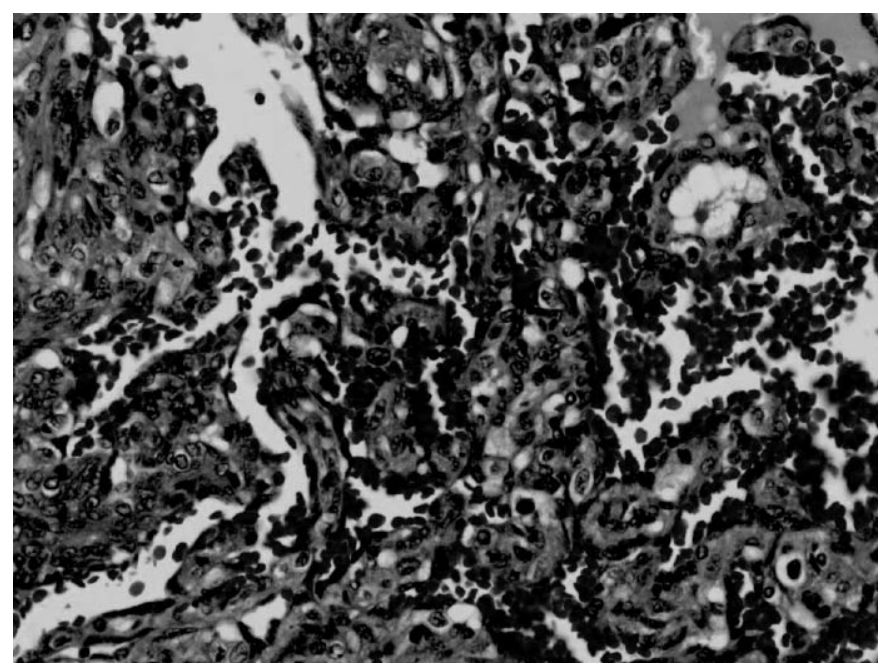

Fig. 1. Atypical endothelial cells with numerous mitotic figures and hyperchromatic nuclei lining the vascular structures $(\mathrm{H} \& \mathrm{E} \times 400)$.

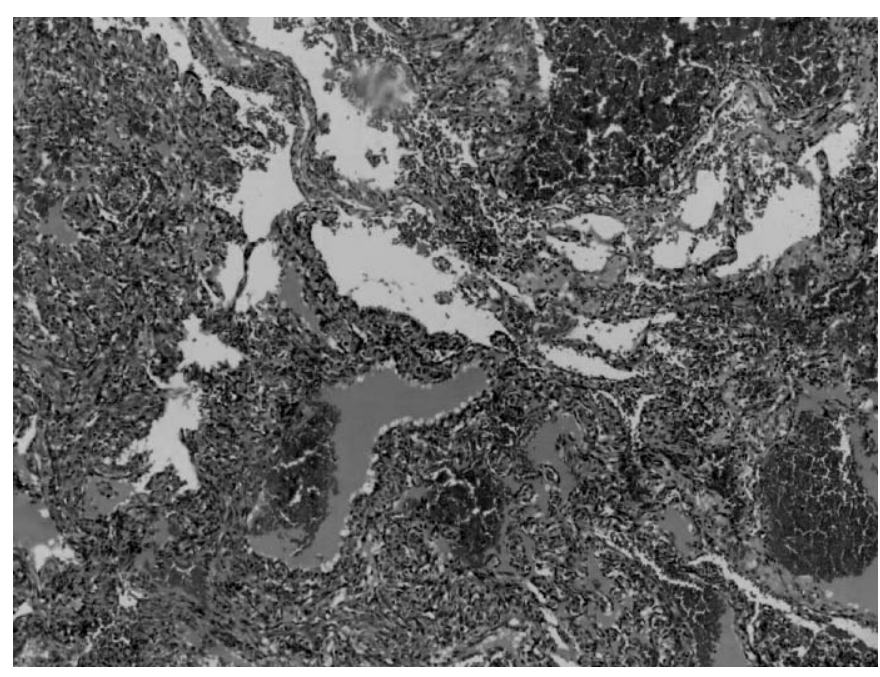

Fig. 2. Poorly differentiated tumor with area of necrosis and massive hemorrhage $(\mathrm{H} \& \mathrm{E} \times 200)$.

\section{Discussion}

Breast angiosarcomas are very rare and tend to affect women in their 3rd or 4th decade of life (mean age 38 years). Half of the patients may be misdiagnosed due to the scarcity of the disease and clinical similarity with benign lesions. A typical clinical manifestation is a rapidly enlarging painless mass deeply embedded in the breast tissue. $12 \%$ of patients present with initial diffuse enlargement and blocks of calescence of the affected breast. Some cases with persistent subcutaneous bleeding tend to be ignored as the tumor may be masked. A purple discoloration of the overlying skin due to tumor infiltration is a frequent symptom; however involvement of the underlying muscles is rare $[1,3,5]$. Breast angiosarcomas are aggressive and tend to recur locally and metastasize widely. They mainly spread hematogenously while lymphatic metastasis is generally absent. The most frequent sites of distant metastasis are lung, liver, bone, and skin [3]. The prognosis is generally poor and based primarily on tumor size, tumor grade, completeness of surgery, and performance status. Angiosarcomas secondary to irradiation, local relapses, and distant metastases are adverse prognostic indicators [4, 6-8].

Surgical resection is recommended as the primary treatment. Adjuvant radiotherapy and chemotherapy are considered helpful to reduce the local recurrence rate in poorly differentiated tumors [9], but a real effect on survival is not proven. Palliative chemotherapy is the basic concept of treatment in advanced disease. Anthracycline-based regimens have emerged, by consensus, as the standard first-line therapy for angiosarcomas as well as most other subtypes of soft tissue sarcomas [6]. Paclitaxel and liposomal doxorubicin have also shown some activity [10]. However there is still no general agreement about a standardized therapy in patients progressing on anthracycline. It has been reported that trofosfamide plus gemcitabine are feasible and can be safely 


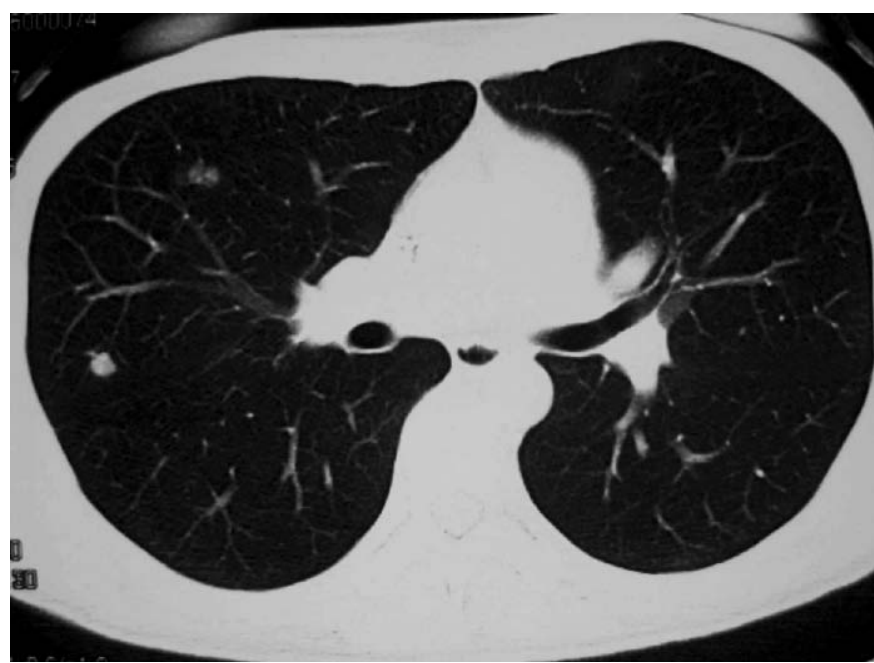

Fig. 3. Computed tomography scan at first presentation (8 November 2009) prior to chemotherapy showing pulmonary metastasis.

administered [11]. Furthermore, docetaxel has demonstrated a certain efficacy [12], and capecitabine alone or combined with docetaxel have also shown some effect [13-16]. However the efficacy of these regimens is limited, and only a few patients can benefit from second-line treatment [17]. In the case reported here, we used a GVP regimen after failure of $3 \mathrm{cy}-$ cles of MAID chemotherapy and achieved complete remission of the lung metastases upon completion of 6 treatment cycles. Hence, the GVP regimen seems to be an option as a

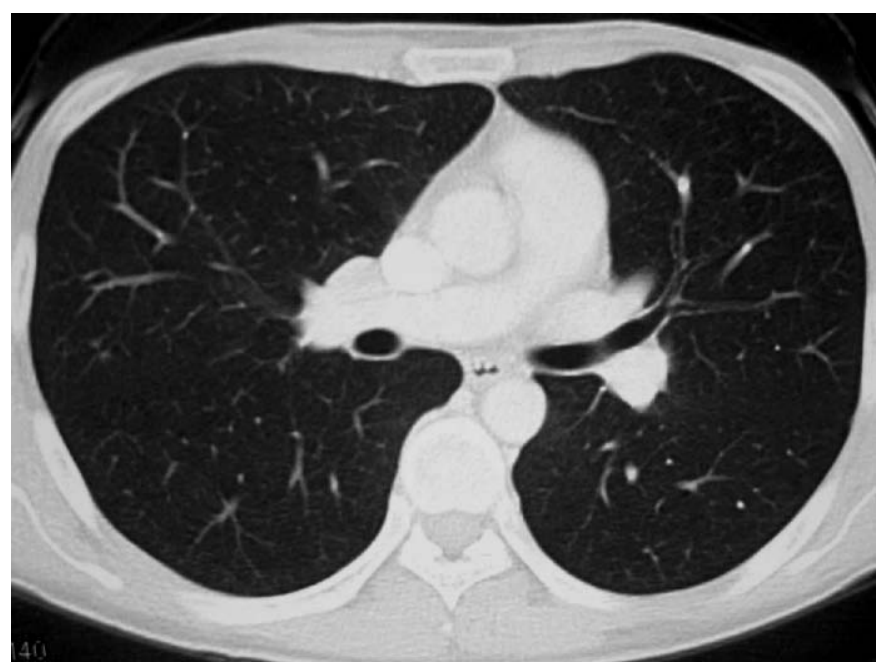

Fig. 4. Computed tomography scan after 6 cycles of GVP chemotherapy (29 March 2010) revealing complete disappearance of the pulmonary lesions.

second-line treatment modality for anthracycline-resistant breast angiosarcomas. More trials are needed to confirm its clinical value.

\section{Disclosure Statement}

The authors confirm that there was no conflict of interest.

\section{References}

1 Donnell RM, Rosen PP, Lieberman PH, et al: Angiosarcoma and other vascular tumors of the breast. Am J Surg Pathol 1981;5:629-42.

$>2$ Luini A, Gatti G, Diaz J, et al.: Angiosarcoma of the breast: the experience of the European Institute of Oncology and a review of the literature. Breast Cancer Res Treat 2007;105:81-5.

3 Chen KT, Kirkegaard DD, Bocian JJ: Angiosarcoma of the breast. Cancer 1980;46:368-71.

4 Zhou SA, Wei H, Ding K: A rare case of metachronous bilateral angiosarcoma of the breast. Breast Care (Basel) 2009;4:405-7.

5 Merino MJ, Carter D, Berman M: Angiosarcoma of the breast. Am J Surg Pathol 1983;7:53-60.

6 Van Glabbeke M, van Oosterom AT, Oosterhuis JW, et al.: Prognostic factors for the outcome of chemotherapy in advanced soft tissue sarcoma: an analysis of 2,185 patients treated with anthracycline-containing first-line regimens - a European Organization for Research and Treatment of Cancer Soft Tissue and Bone Sarcoma Group Study. J Clin Oncol 1999;17:150-7.
Sher T, Hennessy BT, Valero V, et al.: Primary angiosarcomas of the breast. Cancer 2007;110:173-8.

8 Rosen PP, Kimmel M, Ernsberger D: Mammary angiosarcoma. The prognostic significance of tumor differentiation. Cancer 188;62:2145-51.

-9 Silverman LR, Deligdisch L, Mandeli J, et al.: Chemotherapy for angiosarcoma of the breast: case report of 30-year survival and analysis of the literature. Cancer Invest 1994;12:145-55.

10 Skubitz KM, Haddad PA: Paclitaxel and pegylated-liposomal doxorubicin are both active in angiosarcoma. Cancer 2005;104:361-6.

11 Hartmann JT, Patel S: Recent developments in salvage chemotherapy for patients with metastatic soft tissue sarcoma. Drugs 2005;65:167-78.

12 Isogai R, Kawada A, Aragane Y, et al.: Successful treatment of pulmonary metastasis and local recurrence of angiosarcoma with docetaxel. J Dermatol 2004;31:335-41.

13 Hensley ML, Maki R, Venkatraman E, et al.: Gemcitabine and docetaxel in patients with unresectable leiomyosarcoma: results of a phase II trial. J Clin Oncol 2002;20:2824-31.
14 Okuno S, Edmonson J, Mahoney M, et al.: Phase II trial of gemcitabine in advanced sarcomas. Cancer 2002;94:3225-9.

15 Patel SR, Gandhi V, Jenkins J, et al.: Phase II clinical investigation of gemcitabine in advanced soft tissue sarcomas and window evaluation of dose rate on gemcitabine triphosphate accumulation. J Clin Oncol 2001;19:3483-9.

16 Leu KM, Ostruszka LJ, Shewach D, et al.: Laboratory and clinical evidence of synergistic cytotoxicity of sequential treatment with gemcitabine followed by docetaxel in the treatment of sarcoma. J Clin Oncol 2004;22:1706-12.

17 Minchom A, Jones RL, Fisher C, et al.: Clinical benefit of second-line palliative chemotherapy in advanced soft-tissue sarcoma. Sarcoma 2010;2010:264360. 